\title{
The Location of Literature Curriculum under the Condition of Modern Educational Techniques
}

\author{
Chuanbo Huang \\ Dezhou University, Dezhou, Shandong, China \\ hcbdzxy@126.com
}

\begin{abstract}
Multimedia teaching has become an important branch of reform in 21st century education already. A great deal of defects and deficiencies in the traditional literature teaching have been overcome and remedied in multimedia teaching. But because its acceptation and using have to go through a long time and many teachers are low- level in the computer application, it has brought about a great deal of questions in teaching. How to make an accurate location of multimedia teaching has become a question we must face. We must define that modern educational techniques is the complementary means of teaching. We should use modern educational techniques rationally, lead students to study omni-directionally, promote the results of learning, and stimulate students' independent learning ability.
\end{abstract}

Index Terms - literature curriculum, modern educational techniques

Multimedia teaching has become an important branch of reform in 21 st century education already. The blackboard is replaced by the screen projection, which is completely subversive for traditional classroom structure of platform, chalk and blackboard. Especially during the teaching process of literature curriculum, students are really strong sense of the digital information of modern high technology from slide transition through the modes of propagation of modern teaching media. A great deal of defects and deficiencies in the traditional literature teaching have been overcome and remedied in multimedia teaching. Meanwhile, the utilization of modern educational techniques can well solve the sharp contradiction between the vast course content in literature curriculum system and the hours that the literature courses are being compressed constantly at present, and improve teaching quality effectively within limited time. The literature course teaching under modern educational techniques has made a prominent effect in training students' innovation ability and developing their individual character etc.

However, multimedia teaching, as the supplementary means of good teaching, has not been utilized abundantly effectively in realistic teaching process. Some even use it wrongly and reduce the actual teaching result instead. It should be our basic principle of making multimedia courseware to pursue the depth, aesthetic feeling and the high efficiency, but in the course of using the multimedia actually, a lot of teachers make it simple. For example, some teachers think that multimedia teaching is a simple form of the application of PPT. They input their lecture into computer and substitute traditional lecture notes with PPT. Some teachers utilize the resources of the network to download some network coursewares to give lessons briefly, which have lost original due ideological content and artistry of literature course of the beginning while lightening their workload. Some teachers use the only technological diagram literature content of the modern sound briefly in order to attract students. Such vulgar products lead to fawn on customs and become superficial which is that literature object to all the time. It gets half the result with twice the effort. A lot of teachers are not suitable to give lessons with multimedia because of their limited PC skills at all. As the new developing result, modern teaching technology is accepted and even become one of the evaluation indexes of discipline extensively. But because its acceptation and using have to go through a long time and many teachers are low- level in the computer application, it has brought about a great deal of questions in teaching. How to make an accurate location of it is a question we must face. As the new developing result, seldom pay close attention to the location of literature course teaching under modern education skill.

Present university students have tremendous difference with traditional students. They attach importance to utility value and ignore quality. They study for the material gain but not for humanism. But we must know that literature and culture have enormous potentiality in the process of moulding people. As teachers of literature curriculum, we should hold our ground of aesthetic value and spiritual orientation on the practical basis. The application of modern education skill can relieve this question to a great extent. A lot of abstract contents will be direct and simple in the teaching of literature by using multimedia, which is propitious to the students' accepting. Picture, melodized sound, excellent video cartoon with abundant color, can improve students' study interest. If we want to make it come true really, we should use modern educational techniques in the teaching, and make a correct course presentation.

First, we must define the primary and secondary relation between modern educational techniques and teacher's teaching.

We should make clear the localization that modern educational techniques is the complementary means of teaching, otherwise just put the cart before the horse. In any case, it is the base of our teaching that knowledge should be taught and students' innovation ability is trained. The application of modern educational techniques helps to realize this 
purpose. We can't only try to please students' ears and eyes in teaching by simple technicalization teaching, which lead to that students make temporary satisfaction and ignore the fundamental thing. So, every teacher should define that our teaching is to rely mainly on teaching knowledge. We must define the localization of course.

Second, use modern educational techniques rationally, lead students to study omni-directionally, and promote the results of learning.

Using modern educational techniques can show abundant content and aesthetics result of literature and language. Literature courses are important courses of training student's language ability and estheticism. Multimedia teaching terms can make learn-for-learn student become voluntarily passively. It can avoid students' trouble of recording the note, solve the focal point, and break through the difficult point, which strengthens the teaching result and improves teaching quality. Using modern educational techniques to carry on teaching rationally, can make the picture and text, seeing and hearing combine, and strengthen student's understanding, memory ability. While using modern educational techniques, it adopts tableau vivant of sound and draw and luxuriant, the means combined in seeing and hearing, and set up different literary language teaching situation modes, which can help students to accelerate perceiving and understanding the process of the literary language, get up students' many kinds of sense organs participate in the network teaching activity. Thus they study more swiftly, and remember firmer.

Third, use modern educational techniques rationally, and stimulate student's independent learning ability.

Literature curriculum has very abundant content, but at present its course times has been compressed constantly to adapt the innovation of Chinese higher education. In this case, using modern educational techniques can solve the sharp contradiction between tremendous course content of literature courses teaching and limited time. Under the condition of modern educational techniques, literature course can offer the abundant, utilized conveniently literary language material which have avoided teacher's uninteresting and dull spoon-feed teaching. Student can take issue into think or listen to dub in background music recording and read aloud, enter situation of the literary language directly, and many sense organ can be exposed to literary language. Among large linguistic context, they have a taste of Chinese and foreign literature, aesthetic feeling of culture unconsciously joyfully and happily. It can stimulate students' problem consciousness and enthusiasm of study, make students correct the attitude towards study, and train the habit of student's independent study. Under the condition of modern educational techniques, we should instruct students how to list the studying, creative study goal timely, carry on creative research study, and pay close attention to students' research learning method, and train their ability of making study. At the same time it can train their ability of working alone, cooperating with others and searching, choosing, summing up the ability of information, etc.

Modern educational techniques can offer rich, colorful, lively, concrete and visual thinking material for literature courses, which can be expected to widen the space-time of the traditional classroom demarcation line, increase the amount of information of the classroom, accelerate the rhythm of the classroom, widen the student visual field, and further improve teaching quality. Meanwhile, assisting the teaching means of multimedia to activate the literature classroom and pay attention to the teaching ideas to upgrade, absolutely not replace office coaching that should be excellent with the information technology. It should be clear for every teacher engaged in literature courses.

\section{REFERENCES}

[1] Ge Ruige. (2009). Talk about some mistakes of combining Chinese discipline and modern educational techniques. New Course, (3):P13-14

[2] Yan Qiuhong. (2009). The function of modern educational techniques in Literature Appreciation. Art Education, (2):P 9-21

[3] Gao Renxiong. (2002). Attempt of modern educational techniques in the teaching of classical literature. Gansu Science and Technology, (5) :P40

[4] Sun Xuexia. (2008). The realization of traditional education and realization of modern technology in the literature teaching of the pre-Qin period. scientific and technical information, (3):P189

[5] Wen Baolin. (2008). Adopt modern education skill to activate the Chinese classic literature teaching. Journal of Tiansui's teachers college, (3):110-113

[6] Liu Jie. (2007). On the reform of education under the modern information technology. educational innovation, 6)P9-10

Chuanbo Huang was born in Dezhou, China in 1976. He received his M.A. degree in Chinese modern literature from Nanjing University, China in 2003.

He is currently a lecturer in Dezhou University, Dezhou, China. His research interests include Chinese modern and contemporary literature and culture.

Mr. Huang is a member of Research Academy of Modern Chinese Literature. 